\title{
Institucionalização do Modelo da Gestão Integrada da Escola na Rede Estadual de Ensino do Rio de Janeiro
}

\author{
Institutionalization of the Integrated School Management Model \\ in the Public School System of Rio de Janeiro
}

Lucia Helena Esteves Pereira

Universidade Federal Fluminense

Sandra Regina Holanda Mariano

Universidade Federal Fluminense

Joysi Moraes

Universidade Federal Fluminense

Bruno Francisco Batista Dias

Universidade Federal Fluminense

Recebido em 10 de abril de 2018

Aprovado em 12 de março de 2019

\section{RESUMO}

Este artigo discute, em que medida, as práticas inerentes ao modelo da Gestão Integrada da Escola (GIDE) implementadas nas escolas estaduais do Rio de Janeiro passaram a fazer parte da rotina da organização escolar, ou seja, em que medida foram institucionalizadas ou não. O processo de institucionalização, caracterizado por possuir, pelo menos, três fases, habitualização, objetificação e sedimentação (TOLBERT e ZUCKER, 1999), foi analisado sob a perspectiva dos docentes. Foi realizada uma survey com professores da Rede Estadual de Educação, utilizando o Survey Monkey. O nível de confiança adotado foi de $92 \%$ e, tendo como referência o universo em estudo de 54.000 professores, havia a necessidade de alcançar, pelo menos, 156 respondentes. Foram obtidas 189 respostas. Os resultados apontam que a implementação da GIDE organizou e padronizou rotinas administrativas que permitiram a maior organização do sistema educacional do estado. Estas práticas administrativas foram sedimentadas. Entretanto, as práticas pedagógicas dos docentes, em sala de aula, não foram alteradas, ou seja, as mudanças sugeridas pela GIDE não foram extensíveis à sala de aula. Só houve mudança, de fato, nos processos administrativos. Este foi um dos principais achados desta pesquisa: no espaço destinado ao exercício da burocracia profissional não ocorreram mudanças significativas. Uma das principais características deste tipo de estrutura é a autonomia individual que permite grande liberdade de controle do próprio trabalho por parte do profissional, como no caso dos docentes em sala de aula (CLABAUGH e ROZYCKI, 1990; BIDWELL, 2001; MINTZBERG, 2003).

Palavras-chave: Institucionalização; Modelo de Gestão Integrada da Escola (GIDE); Escolas públicas. 


\section{ABSTRACT}

This paper discusses how the practices inherent to the "Integrated School Management Model" (GIDE) that was implemented in the public schools of Rio de Janeiro have become part of the routine of school organization, that is, to what extent they were institutionalized or not. The process of institutionalization, characterized by having at least three phases, habitualization, objectification and sedimentation (TOLBERT and ZUCKER, 1999), was analyzed from the perspective of the teachers. A survey was conducted with teachers from the State Education System, using Survey Monkey. The confidence level adopted was $92 \%$ and, based on the study universe of 54.000 teachers, there was a need to reach at least 156 respondents. A total of 189 responses were obtained. The results indicate that the implementation of GIDE organized and standardized administrative routines that allowed the larger organization of the state educational system. These administrative practices were consolidated. However, the pedagogical practices of teachers in the classroom were not changed, that is, the changes suggested by GIDE were not extensible in the classroom. There was only change, in fact, in administrative processes. This was one of the main findings of this research: in the space destined to the exercise of the professional bureaucracy did not occur significant changes. One of the main characteristics of this type of structure is the individual autonomy that allows great freedom of control of the own work by the professional, as in the case of teachers in the classroom (CLABAUGH and ROZYCKI, 1990; BIDWELL, 2001; MINTZBERG, 2003).

Keywords: Institutionalization; Integrated School Management Model (GIDE); Public schools.

\section{Introdução}

A Organização para Cooperação e Desenvolvimento Econômico (OCDE) vem buscando intervir de modo cada vez mais incisivo nos sistemas públicos de ensino de seus países membros e convidados, entre eles, o Brasil. Para tanto, foi criado em 2000, o Programa Internacional de Avaliação de Alunos, conhecido como Programme for International Student Assessment (PISA), cujo objetivo é avaliar o domínio dos estudantes de quinze anos em matemática, linguagem e ciências. O objetivo é mensurar a aptidão e competências dos estudantes, necessárias à vida adulta. A partir dos resultados obtidos no exame, por cada país, a OCDE propõe modificações, em termos de políticas públicas, que permitam a melhoria dos sistemas educacionais, segundo seus critérios de qualidade.

De forma paralela ao PISA, e com parâmetros similares, o Brasil estruturou, em 2005, um modelo próprio para acompanhar e avaliar o desempenho dos estudantes 


\section{Frm entioará}

ISSN: 1984-6444 | http://dx.doi.org/10.5902/1984644432139

brasileiros: o Sistema de Avaliação da Educação Básica (Saeb), cujo objetivo consiste na geração de indicadores para melhoria dos instrumentos de gestão das escolas públicas. Com os resultados do Saeb, o Inep calcula o Índice de Desenvolvimento da Educação Básica (Ideb) - um indicador de qualidade educacional que combina informações de desempenho em exames padronizados (Prova Brasil ou Saeb) e rendimento escolar do educando (INEP, 2015). A partir dos resultados do Ideb, os governos federal, estaduais e municipais, também, podem propor ações, em termos de políticas públicas, que permitam a melhoria dos seus sistemas educacionais.

Os resultados das avaliações do Saeb de 2005, 2007 e 2009 evidenciaram um paradoxo em relação à situação da qualidade da educação do estado do Rio de Janeiro: economia em acelerado crescimento, mas baixo nível de aprendizagem estudantil, principalmente, se comparado aos outros estados brasileiros. Em 2009, por exemplo, a divulgação do resultado da qualidade do aprendizado da educação básica

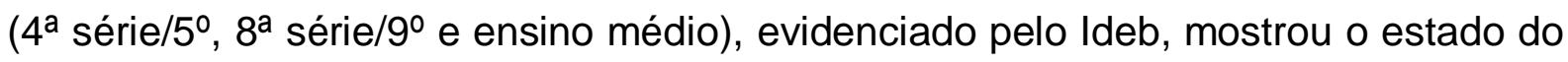
Rio de Janeiro na 26a posição no ranking nacional, acima apenas do estado do Piauí. Em outros termos, apesar do estado possuir o $3^{\circ}$ maior PIB nacional, os resultados da educação eram inferiores à maioria dos estados.

Como resposta aos resultados alcançados naquela época, a Secretaria de Estado de Educação do Rio de Janeiro (SEEDUC-RJ) implementou, a partir de 2010, um modelo de gestão nas escolas estaduais, cujas principais ações foram estruturadas na forma de uma metodologia de gestão intitulada Gestão Integrada da Escola (GIDE). No nível da escola, a GIDE orientava a necessidade de que cada unidade organizativa definisse sua visão, missão e valores, bem como metas de desempenho que permitissem acompanhar a evolução do processo de ensinoaprendizagem dos educandos.

Segundo a SEEDUC-RJ (2013; 2014), as mudanças de gestão (pedagógica e administrativa) introduzidas pela GIDE apresentaram um efeito positivo sobre a qualidade da educação do estado. Já nos resultados do Ideb de 2011, o estado saiu da $26^{\text {a }}$ posição e passou para a $15^{\text {a }}$ posição no ranking nacional. Em 2013, houve novo avanço, que permitiu ao estado alcançar a $4^{\underline{a}}$ posição entre os estados da federação. Entretanto, apesar do reconhecimento que, possivelmente, a melhoria dos 


\section{工 Wus entioargá}

ISSN: 1984-6444 | http://dx.doi.org/10.5902/1984644432139

resultados alcançados esteja vinculada à implementação da GIDE, houve resistências à sua execução no âmbito das escolas, principalmente, por parte dos professores. $O$ sindicato dos professores, por exemplo, se opôs à implantação da GIDE, alegando que a mesma seja baseada na transposição de critérios utilizados em empresas para o contexto escolar.

Nesse sentido, os resultados aqui apresentados são resultados de uma pesquisa que investigou, à luz da Teoria Institucional (MEYER e ROWAN, 1977; ZUCKER, 1977; POWELL e DiMAGGIO, 1983; ZUCKER, 1987; POWELL e DiMAGGIO, 1990; TOLBERT e ZUCKER, 1999; MACHADO-DA-SILVA e GONÇALVES, 1999; KIRKBESOGLU, 2012), de que modo as mudanças implementadas pela GIDE foram incorporadas pelos professores que integram a rede estadual de ensino público do Rio de Janeiro e em que medida as práticas continuaram a serem adotadas. Em outros termos, foi verificado em que fase do processo de institucionalização (habitualização, objetificação e sedimentação) (TOLBERT e ZUCKER, 1999), as práticas organizativas implementadas pela GIDE nas escolas estaduais do Rio de Janeiro se encontram.

\section{A Gestão Integrada da Escola (GIDE)}

A Gestão Integrada da Escola, modelo de gestão proposto pela Secretaria de Estado de Educação do Rio de Janeiro (SEEDUC-RJ), tem como objetivo auxiliar a escola a identificar seus problemas e agir nas principais causas, visando a melhoria do processo de ensino e aprendizagem (GODOY e MURICI, 2009). Este modelo de gestão proposto pela SEEDUC-RJ integra os aspectos políticos, estratégicos e gerenciais específicos da área educacional, com foco, principalmente, nos resultados do processo ensino-aprendizagem, o que implicaria, também, na melhoria dos indicadores da educação do estado.

A GIDE é utilizada como uma metodologia que pode auxiliar as escolas a resolver os problemas que impedem o alcance das metas propostas pelo Ministério da Educação, observadas no Índice de Desenvolvimento da Educação Básica (Ideb). Essa metodologia, segundo Valle (2012), associa o planejamento de cada escola à 


\section{Fusm entubará}

ISSN: 1984-6444 | http://dx.doi.org/10.5902/1984644432139

evolução do processo de ensino-aprendizagem, apoiado no diagnóstico (análise de resultados), desenvolvimento (metas, estratégias e planos de ação), implementação da proposta curricular e dos planos de ação, acompanhamento dos planos e resultados, ações corretivas e divulgação de resultados, com o registro de boas práticas.

O indicador básico da GIDE é o Índice de Formação de Cidadania e Responsabilidade Social (IFC/RS). Este indicador fornece a cada escola informações necessárias para uma análise detalhada sobre seus resultados e os meios que influenciam estes resultados. Godoy e Murici (2009, p. 17) assinalam que o IFC/RS analisa a dimensão 'resultados' que compreende as avaliações internas e externas da escola e capacidade de autossustentação; a dimensão 'condições ambientais' que enfatiza a saúde física e mental, participação política, convivência, estrutura física e serviços; e a dimensão 'ensino-aprendizagem' que abrange a comunidade escolar (gestor, professores, alunos e pais).

A implementação da GIDE nas escolas contou com o apoio de Agentes de Acompanhamento da Gestão Escolar (AAGEs). Os AAGEs eram professores da rede estadual que passaram por processo seletivo interno e foram capacitados na metodologia da GIDE para realizar a multiplicação, orientação e acompanhamento das escolas. Entre suas principais atribuições estavam: treinar gestores, professores e demais servidores da escola para que pudessem executar as ações propostas no plano de ação da Secretaria de Educação; providenciar suporte à implementação da metodologia GIDE, realizando atividades de apoio e sistematizando as atividades para os membros da organização escolar; e criar um clima de cooperação e comprometimento com os resultados da escola, de modo que as pessoas trabalhassem em prol do alcance das metas estipuladas nas avaliações externas.

Os AAGEs deveriam, ainda, orientar cada unidade escolar a: identificar os problemas da escola; definir metas; e elaborar planos de ação para solução dos problemas identificados e melhoria dos resultados da escola. Ao longo de cada ano, a execução das ações era monitorada e acompanhada para a correção de medidas e/ou a padronização de boas práticas (SEEDUC, 2014). 


\section{Fusy entinabal}

ISSN: 1984-6444 | http://dx.doi.org/10.5902/1984644432139

Desta forma, após a implementação da GIDE, algumas práticas organizativas foram introduzidas na rotina das escolas, tanto no aspecto administrativo como no pedagógico, tais como: a) gestão das rotinas escolares por meio de um sistema de informação, o Conexão Educação, implantado em 2009; b) definição de calendário escolar contemplando os eventos pedagógicos e de gestão da escola; c) aplicação das avaliações externas do Sistema de Avaliação da Educação do Estado do Rio de Janeiro (SAERJ), criado em 2008 com o objetivo de promover uma análise do desempenho dos alunos da rede pública do Rio de Janeiro nas áreas de Língua Portuguesa e Matemática - Saerjinho (bimestral) e SAERJ (anual); d) implantação de currículo básico unificado; e) estabelecimento de painel de gestão à vista e; f) acompanhamento e avaliação sistemática do desempenho escolar, reforçando os objetivos da avaliação nos aspectos conceituais e operacionais; e g) aplicação dos instrumentos de avaliação, análise dos resultados por estudante, com propostas de recuperação de estudos, progressão parcial e acompanhamento do conselho de classe (SEEDUC, 2014).

De acordo com a GIDE, aos docentes caberia: registrar as práticas pedagógicas bem-sucedidas em sala de aula, executar os planos de curso, participar das reuniões de conselho de classe, ser pontual, não faltar ao trabalho, realizar aulas atrativas, cumprir o Currículo Básico, lançar notas e frequência dos estudantes no Conexão Educação no prazo. Competia-Ihes, ainda, o cumprimento da Portaria SEEDUC/SUGEN no419/2013 que definia a aplicação de, pelo menos, três instrumentos avaliativos diferenciados com pesos definidos pelo professor, a cada bimestre e, quando necessário, organizar atividades de recuperação de estudos para os discentes que apresentassem baixo rendimento.

Assim, a partir da implementação da GIDE, várias práticas organizativas foram implementadas ou intensificadas no cotidiano das escolas e na rotina dos professores, visando à sistematização das rotinas de gestão das escolas do estado. Borges (2013, p. 27) ressalta que "esses modelos padronizados têm a função de evitar que os gestores caminhem com suas próprias estratégias diante das demandas e da abrangência dos problemas escolares". Mas, ao mesmo tempo, permitem à Secretaria de Educação providenciar maior suporte às escolas, além de um acompanhamento 


\section{FEM Eutioará}

ISSN: 1984-6444 | http://dx.doi.org/10.5902/1984644432139

mais próximo e regular, de modo que as mesmas possam, inclusive, conhecer práticas exitosas de outras escolas e ter apoio para implementar planos de ação cujos objetivos sejam a melhoria da qualidade de educação.

\section{Teoria Institucional}

As escolas são organizações que buscam desempenhar seu papel na sociedade, com o dever de contribuir para transformação e desenvolvimento social, produzindo algum impacto para os indivíduos e para a sociedade (CLABAUGH e ROZYCKI, 1990; BIDWELL, 2001). Portanto, uma organização com uma estrutura social que aloca recursos e providencia benefícios simbólicos e substanciais à sociedade. Faz-se necessário reconhecer que a organização escolar é construída por pessoas e, como tal, é marcada por disputas. Principalmente, as escolas públicas, posto que estão imersas em uma estrutura hierárquica federal, estadual ou municipal que define suas estruturas, metas, currículos, seus gestores, em inúmeros casos, e, paradoxalmente, se propõe às mesmas uma gestão democrática.

Permita-se, então, uma digressão para tratar de como é definido o gestor da maioria das escolas no Brasil. Tal informação permite vislumbrar, pelo menos, parte da incoerência posta na escola e com a qual a comunidade escolar precisa lidar (SOUZA e GOUVEIA, 2010). De acordo com o Instituto Brasileiro de Geografia e Estatística (IBGE, 2015), em 74,4\% dos municípios brasileiros, os diretores de escolas da rede municipal de ensino são escolhidos apenas com base em indicação política. Isto é, dos 5.570 munícipios existentes no Brasil, 4.146 municípios, recorrem somente à indicação política para a escolha dos diretores. Como assinalado pelo IBGE (2015, p. 42), "a livre indicação dos diretores escolares pelos poderes públicos locais abre espaço para as formas mais usuais de clientelismo, além de não garantir o respaldo da comunidade escolar nem a qualificação técnica dos diretores" necessária ao exercício do cargo.

Nestes termos, nas escolas públicas, é comum que mudanças aconteçam por meio da implementação de novas maneiras de organizar e realizar o trabalho, como foi o caso das escolas estaduais do Rio de Janeiro, definidas a partir de uma abordagem top-dow (HOWLETT; RAMESH; PERL 2003). Há que se verificar se, de 


\section{Tusm entratgá}

ISSN: 1984-6444 | http://dx.doi.org/10.5902/1984644432139

fato, ocorreram a adoção e a incorporação destas práticas organizativas no âmbito da escola e, se ocorreram, em que medida e setores da escola. Em outras palavras, fazse necessário analisar os estágios da institucionalização destas práticas propostas pela Secretaria de Educação no âmbito da escola.

Como destacam Eisenhardt (1988) e Nascimento e Vieira (2016), a ideia-chave por trás da institucionalização é que muitas ações organizativas refletem uma maneira de fazer as coisas que evolui ao longo do tempo e torna-se legitimada dentro de uma organização ou ambiente. Por isso, uma mudança organizacional será bem-sucedida, sob a ótica da Teoria Institucional, somente, se for institucionalizada. Para tanto, as práticas que foram implementadas passaram por diferentes estágios até serem interiorizadas. Esses estágios, no conjunto, representam o processo de institucionalização (GUERREIRO et al, 2005; KOETZ e WERLE, 2012; QUEIROS e LIMA, 2012; BONETTI, ODEH e CARNEIRO, 2014; SCHELBAUER, 2014).

A institucionalização de uma nova prática organizativa requer aprendizado e mudanças de padrões e estruturas já estabelecidos que podem ser questionados ou modificados até a incorporação das novas práticas (MEYER e ROWAN, 1977; ZUCKER, 1977; POWELL e DiMAGGIO, 1983; ZUCKER, 1987; POWELL e DiMAGGIO, 1990; TOLBERT e ZUCKER, 1999; MACHADO-DA-SILVA e GONÇALVES, 1999; KIRKBESOGLU, 2012). De acordo com Machado-da-Silva e Gonçalves (1999, p. 180), o conceito de institucionalização remete ao processo e aos mecanismos que resultam em novas práticas e novas regras. Por esse processo, segundo Meyer e Rowan (1977), comportamentos sociais, obrigações e realidades adquirem um status interiorizado de regra no pensamento e na ação social. Como destacam Brelàz e Alves (2013), depois de institucionalizadas, normas e regras passam a fazer parte do cotidiano organizacional e se refletem na ação social dos seus atores. Assim, quanto maior o grau de institucionalização de uma prática, maior tende a ser sua perenidade, sem que haja necessidade de controle social continuado.

Em outras palavras, o processo de institucionalização emerge cada vez que ações são tornadas habituais pelos membros da organização (ZUCKER, 1977; TOLBERT; ZUCKER, 1999). Machado-da-Silva, Fonseca e Crubellate (2010, p. 92) ainda enfatizam que a institucionalização implica "tanto a mudança como a 


\section{Fusy Eutioará}

ISSN: 1984-6444 | http://dx.doi.org/10.5902/1984644432139

persistência, tanto a imersão social como a autonomia, tanto os níveis microssociais (organizações e agentes individuais) como os planos macrossociais".

A que se saber, todavia, que, embora diferentes estudiosos do processo de institucionalismo assumam perspectivas díspares, tais perspectivas variam em termos do macro ou microfundamento de ação social, reconhecida pelos próprios Powell e DiMaggio (1990). Tolber e Zucker (1999), por exemplo, privilegiam o nível micro de ação e uma visão mais processual da institucionalização, ou seja, os processos internos à organização. Nesta microabordagem se busca compreender as diferentes fases do processo de formação das rotinas organizacionais e se considera o desenvolvimento de rotinas como um processo influenciado por características estruturais (impostas pela organização) e por padrões emergentes de interação entre os membros organizacionais (PROCHNO, 2003). Por esta razão, é comum na literatura a distinção entre níveis de institucionalização (BERGER; LUCKMANN, 1976; SCOTT, 2001; TOLBERT; ZUCKER, 1999) e, no nível em que foi realizada a pesquisa em pauta, a perspectiva de Tolbert e Zucker (1999) se revelou adequada.

Para Tolbert e Zucker (1999), o resultado de uma institucionalização é uma tipificação de ações tornadas habituais por tipos específicos de atores. Nesta concepção, à medida que as ações passam a ser generalizadas, tornam-se habituais a todos os grupos ou a um grupo específico de atores dentro da organização e exigem um mínimo esforço por parte dos atores na tomada de decisão são consideradas institucionalizadas. Assim, quanto mais institucionalizadas forem as rotinas dentro de uma organização, mais facilmente são adotadas pelos novos colaboradores, de forma que a transmissão acontece casualmente, aumentando ainda mais o grau de institucionalização.

Por este motivo, a institucionalização é explicada por Tolbert e Zucker (1999) através dos processos de habitualização (pré-institucionalização), objetificação (semiinstitucionalização) e sedimentação (total institucionalização).

Este conjunto de processos sequenciais (habitualização, objetificação, sedimentação) sugere variabilidade nos níveis de institucionalização, implicando que alguns padrões de comportamento social estão mais sujeitos do que outros à avaliação crítica, modificação e mesmo eliminação. Em 


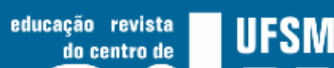 Jilloarga}

ISSN: 1984-6444 | http://dx.doi.org/10.5902/1984644432139

resumo, tais padrões comportamentais podem variar em relação ao grau em que estão imbricados no sistema social e, portanto, variam em termos de seu poder de determinar comportamentos (TOLBERT e ZUCKER, 1999, p. 203).

A habitualização envolve a geração/adoção de novos arranjos estruturais em resposta a problemas ou conjuntos de problemas organizacionais específicos, como também a formalização de tais arranjos em políticas e procedimentos. A adoção de uma nova prática ocorre, frequentemente, com base em soluções já adotadas por outras organizações que estão passando ou já passaram por problemas semelhantes. Esse estágio é classificado como pré-institucionalização (TOLBER E ZUCKER, 1999). DiMaggio e Powell (2005) explicam que o processo de homogeneização de práticas organizativas e ações, especialmente nas organizações públicas, acontece através do isomorfismo institucional. Este tipo de isomorfismo considera que as organizações competem entre si não apenas por recursos e clientes, mas também em busca de poder político e legitimidade institucional com foco em objetivos sociais e econômicos. Neste caso, o processo de mudança organizacional pode ser: coercitivo, mimético ou normativo.

O isomorfismo coercitivo resulta de pressões formais ou informais exercidas por outra organização, ou por força de uma legislação, ou por institucionalização e legitimação por parte do Estado (KIRKBESOGLU, 2012). No caso das escolas da rede de ensino do estado do Rio de Janeiro, a mudança teve sua origem em ordens governamentais. A implementação da GIDE, teve o objetivo de homogeneizar as práticas das escolas estaduais. O isomorfismo mimético deriva das incertezas do ambiente que encorajam a imitação. As organizações imitam outras ou são modeladas por elas. O isomorfismo normativo é derivado da profissionalização e do compartilhamento de um conjunto de normas relativas a uma determinada profissão ou ocupação.

Na objetificação já se observa um movimento em direção a um status mais permanente e disseminado das práticas organizativas implementadas. Nesta fase, denominada de semi-institucionalização, já é possível observar certo grau de consenso social entre os decisores da organização e uma percepção dos benefícios das práticas e dos modelos adotados, passando a adquirir uma base mais normativa. 


\section{Fusy Eutioará}

ISSN: 1984-6444 | http://dx.doi.org/10.5902/1984644432139

As ações e resultados da nova prática vão se generalizando na organização (escola) diminuindo a variação na forma que tomam em diferentes organizações (escolas) (TOLBER E ZUCKER, 1999).

A sedimentação está relacionada à perenidade da prática adotada por longo período de tempo. Apoia-se na continuidade histórica da estrutura e, especialmente, em sua sobrevivência por várias gerações de membros da organização. Porém, nesta fase, dois fatores podem afetar sua difusão e conservação em longo prazo: a existência de grupos de atores afetados adversamente pela prática adotada que podem se mobilizar contra ela; e a falta de resultados demonstráveis associados à adoção da nova prática organizacional (TOLBER E ZUCKER, 1999).

Em outras palavras, as organizações, geralmente, adotam novas práticas, estruturas ou novos modelos em resposta a problemas ou a conjuntos de problemas organizacionais específicos. Portanto, os atores organizacionais internos (diretores de escolas e professores) ou externos (sindicatos de professores) desempenham papel fundamental na permanência da nova prática implementada na organização (escola) ao longo do tempo. Ao perceberem a sua eficácia, podem apoiar e incentivar sua propagação e assim, chegar à total institucionalização. Mas é preciso lembrar que a institucionalização de práticas e ações implementadas não garante sua permanência na organização.

Uma prática institucionalizada permanece em estado de equilíbrio provisório e dinâmico: quanto maior for o seu grau de institucionalização, menor a probabilidade de que seja bruscamente modificada. Por outro lado, mesmo uma prática altamente institucionalizada não é imutável no transcorrer do tempo, já que ela sempre estará vindo à tona no contexto das interações sociais, sendo, portanto, submetida à possibilidade de manutenção ou de alteração nos seus aspectos estruturados ou nas ações decorrentes, os seus aspectos estruturantes (MACHADO-DA-SILVA, FONSECA e CRUBELLATE, 2010, p.96).

Nascimento e Vieira (2016) ponderam, ainda, que, quando se trata de organizações de ensino, a aplicação da teoria institucional se torna relevante pela predominância do caráter democrático observado em sua estrutura, em que os agentes são caracterizados por "elevada massa crítica" o que favorece uma conduta 


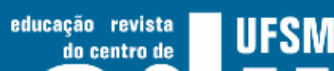 edtothâa}

ISSN: $1984-6444$ | http://dx.doi.org/10.5902/1984644432139

permanente sobre as ações instauradas e desenvolvidas, bem como o questionamento destas práticas.

\section{Procedimentos metodológicos}

A priori, ressalta-se que, como o foco deste estudo foi verificar o nível de institucionalização das práticas organizativas introduzidas nas escolas estaduais pela Secretaria de Educação do Estado do Rio de Janeiro, foram selecionados somente professores que durante o período de inserção e disseminação destas novas práticas estavam no exercício da atividade em sala de aula. Esta foi uma das primeiras perguntas do questionário enviado aos docentes.

Para tanto, foi realizada uma survey com os professores desta Rede. A survey, segundo Babbie (2003), se destina à pesquisa em grande escala e visa apresentar as opiniões das pessoas através de questionários ou entrevistas. O questionário foi disponibilizado, via Survey Monkey, a todos os docentes com endereço eletrônico disponível na Secretaria de Educação, solicitando a participação na pesquisa e explicando seu propósito. Após 15 dias do envio do questionário para a lista de emails, uma nova mensagem foi enviada, solicitando, novamente, a participação dos docentes e reforçando a importância de respondê-lo. Após um (1) mês, a coleta de dados foi encerrada.

O nível de confiança adequado para este tipo de pesquisa é de, pelo menos, 90\% (ACKOFF, 1967; COCHRAN, 1977; HAIR JR. et al., 2009). A fórmula utilizada para cálculo da amostra foi a de Cochran (1977, p. 72-8), tendo como base um erro admissível de $8 \%$. Nestes termos, o nível de confiança adotado nesta pesquisa foi de $92 \%$ e, tendo como referência o universo em estudo de 54.000 professores, havia a necessidade de alcançar, pelo menos, 156 respondentes. Ao término da coleta, foram obtidas 189 respostas.

O questionário, elaborado a partir das construções de Tolbert e Zucker (1999), continha um conjunto de afirmações sobre as práticas introduzidas pela GIDE nas escolas. Buscaram-se evidências da habitualização, objetificação e sedimentação destas práticas, considerando as variáveis estabelecidas através de quatro conjuntos 


\section{Nusm

ISSN: 1984-6444 | http://dx.doi.org/10.5902/1984644432139

de afirmações sobre: implementação da Gestão Integrada da Escola (GIDE), mudanças implementadas na prática diária do professor, percepção de cada docente sobre as mudanças nas práticas de seus colegas e percepção do docente sobre a perenidade das novas práticas implementadas na escola.

Quadro 1 - Variáveis estabelecidas para a análise

\begin{tabular}{|l|l|l|}
\hline $\begin{array}{l}\text { Fases do processo de } \\
\text { institucionalização }\end{array}$ & $\begin{array}{l}\text { Variáveis a serem } \\
\text { observadas }\end{array}$ & $\begin{array}{l}\text { Exemplos de evidências a serem } \\
\text { identificadas }\end{array}$ \\
\hline $\begin{array}{l}\text { Habitualização (pré- } \\
\text { institucionalização) }\end{array}$ & $\begin{array}{l}\text { Mudanças tecnológicas, } \\
\text { mudanças na legislação e } \\
\text { forças do mercado que } \\
\text { pressionam a organização. }\end{array}$ & $\begin{array}{l}\text { Mudanças no processo de trabalho; } \\
\text { mudanças nas rotinas e atividades } \\
\text { resultantes da utilização do Conexão } \\
\text { Educação; Mudança na rotina de trabalho } \\
\text { resultante da implantação da GIDE. }\end{array}$ \\
\hline $\begin{array}{l}\text { Objetificação (semi- } \\
\text { institucionalização) }\end{array}$ & $\begin{array}{l}\text { Consenso se dá pelo não } \\
\text { questionamento dos novos } \\
\text { entrantes. }\end{array}$ & $\begin{array}{l}\text { Adoção das práticas preconizadas pela } \\
\text { GIDE; disseminação das práticas da } \\
\text { GIDE. }\end{array}$ \\
\hline institucionalização) & $\begin{array}{l}\text { Impactos positivos: } \\
\text { resultados demonstráveis } \\
\text { associados à estrutura; } \\
\text { resistência de grupo: } \\
\text { pessoas que são afetadas } \\
\text { adversamente pela estrutura; } \\
\text { defesa de grupo de } \\
\text { interesse: pessoas que são } \\
\text { favoráveis às mudanças na } \\
\text { estrutura. }\end{array}$ & $\begin{array}{l}\text { Entendimento dos professores e } \\
\text { funcionários sobre os objetivos da GIDE; } \\
\text { resistência dos professores e funcionários } \\
\text { a utilizar o Conexão; resistência dos } \\
\text { professores ao SAERJ; resistências dos } \\
\text { professores à GIDE }\end{array}$ \\
\hline
\end{tabular}

Fonte: Elaborado pelos autores

\section{Resultados e discussões}

Os professores que participaram da pesquisa eram $67,21 \%$ do sexo feminino e 32,79\% masculino, com a seguinte de faixa etária: de 25 a 30 anos (7,10\%), de 31 a 35 anos (18,03\%), de 36 a 40 anos (15,85\%), de 41 a 45 anos (16,39\%), de 46 a 50 anos (15,85\%), de 51 a 55 anos (18,03\%), de 56 a 60 anos (6,01\%) e acima de 60 anos $(2,73 \%)$. Em relação à escolaridade, $100 \%$ dos respondentes tinham curso 


\section{Fusy Eutioará}

ISSN: 1984-6444 | http://dx.doi.org/10.5902/1984644432139

superior. Observou-se ainda que $75,41 \%$ eram pós-graduados e, destes, apenas $9,84 \%$ com mestrado e $1,64 \%$ com doutorado.

$72,67 \%$ dos respondentes trabalhavam há mais de dez anos na área de educação, sendo que mais de $85 \%$ trabalham nas escolas estaduais do Rio de Janeiro há, pelo menos, seis anos, o que indica que conhecem a situação da educação pública do estado e já vivenciaram mudanças significativas nas suas práticas organizativas, introduzidas pela Secretaria de Educação.

O mesmo não acontece quando se trata do tempo de atuação dos professores na mesma escola, a atual. Os dados apontam que $72,13 \%$ professores estão há menos de dez anos na mesma escola. Isto é, há certa rotatividade nas escolas do estado e esta pode acontecer por diversos motivos, tais como prioridade do docente por trabalhar mais perto de sua residência, ter se tornado excedente na escola devido à redução de turmas, solicitação do profissional por não se adaptar à escola ou devido a escola ficar em área com alto índice de violência, entre outros.

De acordo com a União dos Professores Públicos no Estado (UPPES, 2018), para cada professor que entrou na rede estadual na última década, 26 se aposentaram. Cerca de cinco professores por dia pedem exoneração, sem contar aposentadorias, mortes e demissões. Segundo o relatório 'Educação em alvo: os efeitos da violência armada nas salas de aula', da Diretoria de Análise de Políticas Públicas da Fundação Getúlio Vargas (FGV/DAPP), faz-se necessário "oferecer condições especiais de contratação para os profissionais que atuam nestas áreas (de risco), de forma a garantir estabilidade nas relações escolares, objetivando diminuir a alta rotatividade de professores" (RUEDIGER, 2017, p. 19). Um problema que tem se tornado cada vez mais grave no Rio de Janeiro.

Segundo Johnson, Berg e Donaldson (2005), a alta rotatividade traz, pelo menos, três tipos de custos: prejuízo instrucional, sofrido pelos estudantes submetidos à troca de professores durante o ano letivo; financeiros para a rede de ensino da qual a escola faz parte; e organizacionais, que dizem respeito à impossibilidade de continuidade de procedimentos e práticas organizativas (Administrativas e Pedagógicas). Nestes termos, passamos a discorrer sobre as práticas organizativas adotadas, a partir da GIDE, e seu grau de institucionalização nas escolas estudadas. 


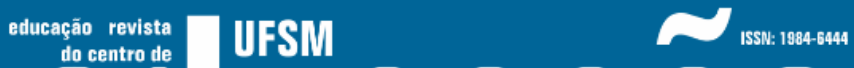

ISSN: 1984-6444 | http://dx.doi.org/10.5902/1984644432139

O Quadro 2 apresenta a percepção dos respondentes a respeito da introdução da GIDE nas escolas, ou seja, como foram introduzidas as práticas organizativas no âmbito das escolas públicas estaduais e como as mudanças resultantes da inserção destas novas práticas nos processos administrativos e pedagógicos impactaram na rotina de trabalho dos docentes.

Quadro 2 - Avaliação da implementação da Gestão Integrada da Escola (GIDE)

\begin{tabular}{|l|l|l|l|}
\hline Afirmação & $\begin{array}{l}\text { Discordo } \\
\text { totalmente } \\
\text { Discordo } \\
\text { em parte }\end{array}$ & $\begin{array}{l}\text { Nem } \\
\text { concordo } \\
\text { Nem } \\
\text { discordo }\end{array}$ & $\begin{array}{l}\text { Concordo } \\
\text { em parte } \\
\text { Concordo } \\
\text { totalmente }\end{array}$ \\
\hline $\begin{array}{l}\text { A avaliação externa diagnóstica Saerjinho passou a ser } \\
\text { aplicada bimestralmente na minha escola. }\end{array}$ & $7,10 \%$ & $5,33 \%$ & $87,57 \%$ \\
\hline $\begin{array}{l}\text { A avaliação externa diagnóstica SAERJ passou a ser aplicada } \\
\text { anualmente na minha escola. }\end{array}$ & $15,38 \%$ & $5,33 \%$ & $79,29 \%$ \\
\hline $\begin{array}{l}\text { Fui informado(a) pela direção da escola sobre a } \\
\text { implementação da GIDE na minha escola. }\end{array}$ & $15,39 \%$ & $7,69 \%$ & $76,90 \%$ \\
\hline $\begin{array}{l}\text { Com a implementação do sistema Conexão Educação, minha } \\
\text { rotina lançamentos de notas foi modificada. }\end{array}$ & $16,57 \%$ & $7,10 \%$ & $76,33 \%$ \\
\hline $\begin{array}{l}\text { Passei a acompanhar os resultados da escola por meio de } \\
\text { gráficos e diagramas divulgados no painel de gestão (mural). }\end{array}$ & $18,93 \%$ & $7,10 \%$ & $73,97 \%$ \\
\hline Com a GIDE, passei a seguir o currículo básico. & $2189 \%$ & $1183 \%$ & $6528 \%$ \\
\hline $\begin{array}{l}\text { Participei das reuniões de acompanhamento realizadas pelo } \\
\text { AAGE sobre as ações da GIDE dentro da escola. }\end{array}$ & $31,37 \%$ & $11,24 \%$ & $57,39 \%$ \\
\hline $\begin{array}{l}\text { Fui informado(a) pelo AAGE sobre a implementação da GIDE } \\
\text { na minha escola. }\end{array}$ & $31,36 \%$ & $13,02 \%$ & $55,62 \%$ \\
\hline $\begin{array}{l}\text { Participei de reuniões com representantes da SEEDUC e da } \\
\text { direção da escola sobre a GIDE. }\end{array}$ & $40,23 \%$ & $9,47 \%$ & $50,30 \%$ \\
\hline $\begin{array}{l}\text { Com a GIDE, passei a elaborar um plano de ação para } \\
\text { alcançar os objetivos de aprendizagem dos meus alunos. }\end{array}$ & $35,51 \%$ & $19,53 \%$ & $44,97 \%$ \\
\hline $\begin{array}{l}\text { Com a implementação do sistema Conexão Educação a minha } \\
\text { rotina de acompanhamento de frequência foi modificada. }\end{array}$ & $42,60 \%$ & $13,61 \%$ & $43,79 \%$ \\
\hline $\begin{array}{l}\text { Com a GIDE, passei a elaborar minhas metas a partir dos } \\
\text { problemas detectados na escola. }\end{array}$ & $38,46 \%$ & $20,12 \%$ & $41,42 \%$ \\
\hline $\begin{array}{l}\text { Na minha opinião, os objetivos da GIDE ficaram claros para } \\
\text { toda a comunidade escolar. }\end{array}$ & $55,03 \%$ & $15,98 \%$ & $29,00 \%$ \\
\hline As minhas aulas passaram a ser mais dinâmicas. & $45,56 \%$ & $26,63 \%$ & $27,81 \%$ \\
\hline $\begin{array}{l}\text { As minhas aulas passaram a ser mais atraentes para os } \\
\text { estudantes. }\end{array}$ & $47,34 \%$ & $26,04 \%$ & $26,63 \%$ \\
\hline
\end{tabular}

Fonte: Dados da Pesquisa

Os resultados apresentados no Quadro 2 referem-se ao processo inicial de implementação da GIDE, ou seja, à habitualização ou pré-institucionalização. 


\section{THEM Eutioará}

ISSN: 1984-6444 | http://dx.doi.org/10.5902/1984644432139

Observa-se que esta etapa de implementação da GIDE nas escolas se deu a partir de pressões formais da Secretaria de Educação que, por sua vez, criou mecanismos de controle sistemáticos para verificar se as práticas (Administrativas e Pedagógicas) foram inseridas na rotina escolar.

As cinco primeiras afirmações são situações que gestores e professores não poderiam se negar a participar porque as avaliações bimestrais e anuais dos estudantes eram externas à escola, realizadas pela própria Secretaria de Educação. Os Agentes de Acompanhamento da Gestão Escolar (AAGEs) acompanhavam as escolas, semanalmente, para manter gestores e professores informados das práticas da GIDE; garantir que professores lançassem as notas dos estudantes, no prazo, na plataforma estadual de monitoramento do desempenho dos estudantes; garantir a divulgação dos resultados das avaliações bimestrais e anuais, por meio de gráficos e diagramas, no painel de gestão (mural - criação da GIDE).

Verifica-se que mais de $70 \%$ dos docentes informaram que adotaram as novas práticas. No entanto, quanto mais a definição do "que fazer" e o processo de trabalho estão sob o controle do professor, maior é a dificuldade de aceitar as novas práticas da Secretaria de Educação.

Note-se que, no que tange à sala de aula, portanto, no que diz respeito às práticas pedagógicas dos docentes, estas, praticamente, não foram alteradas. Este foi um dos principais achados desta pesquisa: no espaço destinado ao exercício da burocracia profissional não ocorreram mudanças significativas. Uma das principais características deste tipo de estrutura é, exatamente, a autonomia individual que permite grande liberdade de controle do próprio trabalho por parte do profissional, como no caso dos docentes em sala de aula (CLABAUGH e ROZYCKI, 1990; BIDWELL, 2001; MINTZBERG, 2003).

Em outras palavras, o que o Quadro 2 mostra é que, embora os docentes tenham tomado conhecimento do que deveria ser feito não implicou no fazer. Pelo menos no âmbito da sala de aula, onde são poucas as alternativas de controle e acompanhamento sistemático e diário dos professores.

Porém, é possível observar sinais de habitualização, posto que houve produção de uma nova rotina de trabalho entre os docentes, pelo menos no que diz respeito ao 


\section{T usm FutlaghaO}

ISSN: 1984-6444 | http://dx.doi.org/10.5902/1984644432139

lançamento de notas, pois os mesmos passaram a utilizar (76,33\%) o Conexão Educação, que integra todos os dados das escolas estaduais do Rio de Janeiro, o que não faziam anteriormente, embora o sistema estivesse disponível há anos. Os professores passaram a acompanhar os resultados da escola, posto que informaram conhecer os resultados do Saerjinho/bimestral (87,57\%) e SAERJ/anual (79,29\%). A exposição pública dos resultados da escola por meio de gráficos e diagramas, no painel de gestão, também foi uma mudança significativa, segundo a percepção de $73,97 \%$ dos respondentes, pois possibilitou o acompanhamento dos resultados da escola por toda a comunidade escolar. No entanto, embora apenas 66,28\% dos respondentes tenham afirmado que passaram a utilizar o Currículo Básico, há que se destacar que houve alteração quanto a esta prática em sala de aula. Muitos docentes discordavam do currículo e, por este motivo, não o utilizavam.

Sobre a perspectiva das mudanças na prática diária do professor, um conjunto de afirmações abordou a sua rotina evidenciada nas ações necessárias ao cumprimento de suas atividades administrativas e pedagógicas. As respostas às afirmações são apresentadas no Quadro 3.

Quadro 3 - Mudanças implementadas na prática diária do professor

\begin{tabular}{|l|l|l|l|}
\hline Afirmação & $\begin{array}{l}\text { Nunca } \\
\text { Quase } \\
\text { nunca }\end{array}$ & $\begin{array}{l}\text { Às } \\
\text { vezes }\end{array}$ & $\begin{array}{l}\text { Quase } \\
\text { sempre } \\
\text { Sempre }\end{array}$ \\
\hline $\begin{array}{l}\text { Utilizo no mínimo três instrumentos de avaliação por bimestre, visando o } \\
\text { desempenho global dos alunos. }\end{array}$ & $0,61 \%$ & $2,45 \%$ & $96.94 \%$ \\
\hline $\begin{array}{l}\text { Ofereço aos alunos atividades de recuperação paralela dentro da própria } \\
\text { etapa de avaliação. }\end{array}$ & $1,84 \%$ & $3,68 \%$ & $94,48 \%$ \\
\hline Cumpro os prazos de entrega de notas. & $1,85 \%$ & $4,94 \%$ & $93,21 \%$ \\
\hline $\begin{array}{l}\text { Participo das reuniões de Conselho de Classe, onde é possível discutir e } \\
\text { replanejar as ações para o próximo bimestre. }\end{array}$ & $0,61 \%$ & $6,71 \%$ & $92,68 \%$ \\
\hline $\begin{array}{l}\text { Executo o plano de curso de acordo com o que foi planejado (conteúdo } \\
\text { programático, formas de avaliação, competências a serem desenvolvidas). }\end{array}$ & $1,84 \%$ & $5,52 \%$ & $92,64 \%$ \\
\hline $\begin{array}{l}\text { Preocupo-me constantemente com o desempenho e a melhoria dos } \\
\text { resultados dos meus alunos e da escola como um todo. }\end{array}$ & $3,09 \%$ & $4,94 \%$ & $91,97 \%$ \\
\hline $\begin{array}{l}\text { Ao final de cada bimestre, faço o lançamento das notas dos alunos no } \\
\text { sistema Conexão Educação dentro do prazo previsto. }\end{array}$ & $5,52 \%$ & $3,68 \%$ & $90,80 \%$ \\
\hline $\begin{array}{l}\text { Trabalho em sala de aula conteúdos e atividades que auxiliam meus } \\
\text { estudantes a melhorar seu desempenho nas avaliações, incentivando-os } \\
\text { para que melhorem cada vez mais seus resultados. }\end{array}$ & $3,07 \%$ & $9,20 \%$ & $87,73 \%$ \\
\hline $\begin{array}{l}\text { Acesso regularmente o currículo básico para conhecer os conteúdos a } \\
\text { serem trabalhados em cada ano e as habilidades a serem desenvolvidas. }\end{array}$ & $1,84 \%$ & $14,72 \% 83,44 \%$ \\
\hline
\end{tabular}




\section{THusm EutlaghaO}

ISSN: 1984-6444 | http://dx.doi.org/10.5902/1984644432139

\begin{tabular}{|c|c|c|}
\hline $\begin{array}{l}\text { Tenho preocupação com o desempenho dos alunos nas avaliações } \\
\text { externas (Saerjinho e SAERJ). }\end{array}$ & $10,43 \%$ & $9,82 \% \quad 79,75 \%$ \\
\hline $\begin{array}{l}\text { Acompanho o desempenho individual dos alunos na disciplina, intervindo } \\
\text { e buscando alternativas para sanar as dificuldades apresentadas. }\end{array}$ & $8,03 \%$ & $20,99 \% 70,99 \%$ \\
\hline $\begin{array}{l}\text { Diante dos resultados alcançados nas avaliações internas e externas } \\
\text { discuto com os alunos os resultados, procurando identificar os avanços e } \\
\text { as dificuldades encontradas por eles na avaliação, buscando minimizar as } \\
\text { falhas para os próximos bimestres. }\end{array}$ & $17,29 \%$ & $20,99 \% 61,73 \%$ \\
\hline As minhas aulas são cada vez mais atrativas para meus alunos. & $6,75 \%$ & $41,10 \% 52,15 \%$ \\
\hline
\end{tabular}

Fonte: Dados da pesquisa

Novamente, o que se observa é que todas as práticas introduzidas pela Secretaria de Educação passíveis de avaliação e monitoramento contínuo foram implementadas pelos professores, tais como: o uso de, pelo menos, três instrumentos de avaliação bimestrais, atividades de recuperação paralela, entrega de notas no prazo, participação nas reuniões de Conselho de Classe, entre outros. No entanto, nas atividades cujas práticas estão, quase que exclusivamente, sob a tutela do professor e onde a Secretaria pouco pode atuar de forma mais incisiva, poucos docentes afirmaram incorporar nas suas rotinas o que foi proposto pela Secretaria. Somente $35 \%$ dos docentes, por exemplo, registram, usam e divulgam práticas bemsucedidas na sala de aula e apenas metade dos professores busca tornar suas aulas cada vez mais atrativas para seus alunos.

Expondo de outro modo, somente as práticas introduzidas pela Secretaria de Educação passíveis de avaliação e monitoramento contínuo estão em processo de objetificação ou semi-institucionalização. As respostas dos docentes apontam para considerável adesão a estas práticas, pois foram implementadas e disseminadas entre os professores de modo satisfatório (90\%). Possivelmente, a compreensão dos benefícios das práticas adotadas, observados nos próprios resultados da escola e nas avaliações externas dos discentes, também, geram uma avaliação positiva das soluções implementadas pela GIDE, que Ihes confere legitimidade normativa, com menor possibilidade de resistência do grupo (TOLBER e ZUCKER, 1999).

O Quadro 4, por sua vez, apresenta a percepção do docente quanto às mudanças observadas nas práticas de seus colegas, a partir da GIDE. 


\section{-7 usw Eutlatba}

ISSN: 1984-6444 | http://dx.doi.org/10.5902/1984644432139

Quadro 4 - A percepção de cada docente sobre as mudanças nas práticas de seus colegas

\begin{tabular}{|c|c|c|c|}
\hline Afirmação & $\begin{array}{l}\text { Nunca } \\
\text { Quase } \\
\text { nunca }\end{array}$ & $\begin{array}{l}\text { Às } \\
\text { vezes }\end{array}$ & $\begin{array}{l}\text { Quase } \\
\text { sempre } \\
\text { Sempre }\end{array}$ \\
\hline $\begin{array}{l}\text { Os professores da minha escola oferecem aos alunos atividades de } \\
\text { recuperação paralela dentro da própria etapa de avaliação. }\end{array}$ & $1.84 \%$ & $9.74 \%$ & $88,96 \%$ \\
\hline $\begin{array}{l}\text { Observo que meus colegas utilizam no mínimo três instrumentos de } \\
\text { avaliação por bimestre, visando o desempenho global dos alunos. }\end{array}$ & $1,94 \%$ & $14,19 \%$ & $83,87 \%$ \\
\hline $\begin{array}{l}\text { Meus colegas preocupam-se constantemente com o desempenho e a } \\
\text { melhoria dos resultados dos seus alunos e da escola como um todo. }\end{array}$ & $2,63 \%$ & $14,87 \%$ & $82,89 \%$ \\
\hline $\begin{array}{l}\text { Meus colegas participam das reuniões de Conselho de Classe, onde é } \\
\text { possível discutir e replanejar as ações para o próximo bimestre. }\end{array}$ & $3,82 \%$ & $16,56 \%$ & $79,61 \%$ \\
\hline $\begin{array}{l}\text { Observo que todos os meus colegas professores trabalham em sala de aula } \\
\text { conteúdos e atividades que auxiliam os estudantes a melhorar seu } \\
\text { desempenho nas avaliações, incentivando-os para que melhorem cada vez } \\
\text { mais seus resultados. }\end{array}$ & $5,33 \%$ & $15,33 \%$ & $79,34 \%$ \\
\hline $\begin{array}{l}\text { Ao final de cada bimestre, observo que os professores de minha escola } \\
\text { fazem o lançamento das notas dos alunos no sistema Conexão Educação } \\
\text { dentro do prazo previsto para o lançamento de notas. }\end{array}$ & $4,58 \%$ & $18,3 \%$ & $77,12 \%$ \\
\hline Meus colegas cumprem os prazos de entrega de notas. & $3,31 \%$ & $23,84 \%$ & $672,84 \%$ \\
\hline $\begin{array}{l}\text { Meus colegas demonstram preocupação com o desempenho dos alunos } \\
\text { nas avaliações externas (Saerjinho e SAERJ). }\end{array}$ & $7,10 \%$ & $22,58 \%$ & $70,32 \%$ \\
\hline $\begin{array}{l}\text { Observo que os professores da minha escola executam o plano de curso de } \\
\text { acordo com o que foi planejado (conteúdo programático, formas de } \\
\text { avaliação, competências a serem desenvolvidas). }\end{array}$ & $8,34 \%$ & $25,64 \%$ & $66,03 \%$ \\
\hline $\begin{array}{l}\text { Diante dos resultados alcançados nas avaliações internas e externas } \\
\text { (Saerjinho), bimestralmente, os professores que trabalham na minha escola } \\
\text { discutem com os alunos os resultados, procurando identificar os avanços e } \\
\text { as dificuldades encontradas por eles na avaliação, buscando minimizar as } \\
\text { falhas para os próximos bimestres. }\end{array}$ & $11,19 \%$ & $24,34 \%$ & $64,47 \%$ \\
\hline $\begin{array}{l}\text { Os professores da minha escola acompanham o desempenho individual dos } \\
\text { alunos na disciplina, intervindo e buscando alternativas para sanar as } \\
\text { dificuldades apresentadas. }\end{array}$ & s. $7,95 \%$ & $29,14 \%$ & $62,92 \%$ \\
\hline
\end{tabular}




\section{Tisy Eutioará}

ISSN: 1984-6444 | http://dx.doi.org/10.5902/1984644432139

\begin{tabular}{|l|l|l|l|}
\hline $\begin{array}{l}\text { Observo que meus colegas acessam regularmente o currículo básico para } \\
\text { conhecer os conteúdos a serem trabalhados em cada ano e as habilidades }\end{array}$ & & & \\
a serem desenvolvidas. & $15,28 \%$ & $33,12 \%$ & $51,59 \%$ \\
\hline $\begin{array}{l}\text { As aulas dos professores da escola onde trabalho são cada vez mais } \\
\text { atrativas para os alunos. }\end{array}$ & $12,99 \%$ & $41,56 \%$ & $45,46 \%$ \\
\hline $\begin{array}{l}\text { Meus colegas registram e divulgam as práticas bem-sucedidas na sala de } \\
\text { aula e na escola para que outros professores também possam utiliza-las. }\end{array}$ & $18,19 \%$ & $38,96 \%$ & $42,86 \%$ \\
\hline
\end{tabular}

Fonte: Dados da pesquisa

O Quadro 4, de modo geral, mostra que mais de $80 \%$ dos respondentes têm a percepção que os colegas, também, adotaram as práticas introduzidas pela GIDE. Mas, somente aquelas que podem ser monitoradas, seja via resultados das avaliações externas, seja através da própria plataforma da Secretaria de Educação, o Conexão Educação. Esses percentuais observados nas respostas sugerem que as práticas podem, ainda que de modo compulsório, ser disseminadas nas escolas.

No entanto, há pouca aceitação das práticas da GIDE na rotina do professor em sala de aula. Provavelmente, a adoção de uma estratégia de caráter mais coercitivo para obter a participação dos docentes, por parte da Secretaria de Educação, ao mesmo tempo em que gerou adesão às práticas passíveis de monitoramento, provocou resistência quando o professor tinha liberdade de escolha. O que pode ser observado, claramente, quando os docentes, no exercício da sua atividade em sala de aula, onde há maior autonomia, não adotaram as práticas da GIDE. Em outros termos, se verifica um processo de objetificação ou semiinstitucionalização das práticas administrativas, mas não das práticas pedagógicas.

Quanto à percepção do docente sobre a perenidade das novas práticas implementadas na escola pela GIDE, os docentes avaliaram, a partir da sua percepção, um conjunto de afirmações sobre as mudanças ocorridas na escola. As respostas podem ser observadas no Quadro 5.

Quadro 5 - A percepção do docente sobre a perenidade das novas práticas implementadas na escola

\begin{tabular}{|l|l|l|l|}
\hline & Discordo & Nem & $\begin{array}{l}\text { Concordo } \\
\text { em parte }\end{array}$ \\
\hline
\end{tabular}




\section{Fusm Eutragál}

ISSN: 1984-6444 | http://dx.doi.org/10.5902/1984644432139

\begin{tabular}{|c|c|c|c|}
\hline Afirmação & $\begin{array}{l}\text { totalmente } \\
\text { Discordo } \\
\text { em parte }\end{array}$ & $\begin{array}{l}\text { concordo } \\
\text { Nem } \\
\text { discordo }\end{array}$ & $\begin{array}{l}\text { Concordo } \\
\text { totalmente }\end{array}$ \\
\hline $\begin{array}{l}\text { Na minha visão, a partir da introdução do sistema Conexão } \\
\text { Educação, várias ações foram padronizadas nas escolas } \\
\text { da rede: informatização de matrículas, quadro de horários, } \\
\text { lançamentos de notas e frequências pelos professores e } \\
\text { boletins. }\end{array}$ & $16,03 \%$ & $8,97 \%$ & $75 \%$ \\
\hline $\begin{array}{l}\text { O Painel de Gestão divulga os resultados da escola para } \\
\text { toda a comunidade e é uma importante prática de } \\
\text { transparência. }\end{array}$ & $27,56 \%$ & $10,9 \%$ & $61,54 \%$ \\
\hline $\begin{array}{l}\text { O Sistema Conexão representou uma melhoria na } \\
\text { organização administrativa da escola. }\end{array}$ & $30,77 \%$ & $8,97 \%$ & $60,26 \%$ \\
\hline $\begin{array}{l}\text { A utilização do Currículo Básico representou um avanço } \\
\text { em relação às práticas anteriores. }\end{array}$ & $29,03 \%$ & $11,61 \%$ & $59,36 \%$ \\
\hline $\begin{array}{l}\text { Após a implementação da GIDE, percebo que a maioria } \\
\text { das ações realizadas dentro das escolas segue uma } \\
\text { mesma metodologia, tanto na área administrativa como na } \\
\text { pedagógica. }\end{array}$ & $27,74 \%$ & $19,35 \%$ & $52,91 \%$ \\
\hline $\begin{array}{l}\text { A avaliação externa diagnóstica bimestral dos discentes é } \\
\text { muito importante para o acompanhamento que faço dos } \\
\text { meus alunos. }\end{array}$ & $40,91 \%$ & $12,99 \%$ & $46,10 \%$ \\
\hline $\begin{array}{l}\text { A avaliação externa diagnóstica anual dos discentes é } \\
\text { muito importante para o acompanhamento que faço dos } \\
\text { meus alunos. }\end{array}$ & $42,31 \%$ & $12,82 \%$ & $44,87 \%$ \\
\hline $\begin{array}{l}\text { A avaliação externa diagnóstica anual dos discentes é } \\
\text { muito importante para o acompanhamento que faço dos } \\
\text { meus alunos. }\end{array}$ & $42,31 \%$ & $12,82 \%$ & $44,87 \%$ \\
\hline $\begin{array}{l}\text { As ações implementadas pela GIDE contribuíram para a } \\
\text { melhoria dos resultados da minha escola. }\end{array}$ & $40,39 \%$ & $16,67 \%$ & $42,95 \%$ \\
\hline $\begin{array}{l}\text { As práticas pedagógicas implementadas pela GIDE } \\
\text { contribuíram para a melhoria do meu trabalho em sala de } \\
\text { aula. }\end{array}$ & $42,86 \%$ & $18,18 \%$ & $38,96 \%$ \\
\hline $\begin{array}{l}\text { Na minha avaliação, a metodologia GIDE contribui para } \\
\text { melhorar as práticas em sala de aula. }\end{array}$ & $43,51 \%$ & $18,83 \%$ & $37,66 \%$ \\
\hline
\end{tabular}




\section{FUsy Eutioará}

ISSN: 1984-6444 | http://dx.doi.org/10.5902/1984644432139

As ações implementadas pela GIDE contribuíram para a melhoria da qualidade da aprendizagem dos alunos da minha escola.

$43,51 \%$ $19,48 \%$ $37,01 \%$

De acordo com os resultados do Quadro 5, 75\% dos respondentes acreditam que uma das principais contribuições da GIDE foi a utilização do Conexão Educação que padronizou muitas das atividades nas escolas da rede estadual do Rio de Janeiro, tais como: informatização de matrículas, quadro de horários, lançamentos de notas e frequências pelos professores e boletins. Práticas fundamentais para a rotina da escola, mas que antes da GIDE não eram cumpridas pelos docentes, embora o Conexão Educação já existisse.

No entanto, somente cerca de $40 \%$ dos respondentes acreditam que as práticas (Administrativas e Pedagógicas) implementadas pela GIDE contribuíram para a melhoria dos resultados da escola e para a melhoria do trabalho do docente em sala de aula. Mais importante, de acordo com os respondentes, menos de $40 \%$ dos docentes acreditam que as práticas introduzidas pela GIDE contribuíram para melhorar as práticas em sala de aula e para a melhoria da qualidade da aprendizagem dos alunos. Há que se ressaltar que os próprios docentes, em sua maioria, não acolheram as práticas da GIDE em sala de aula. Provavelmente, a esfera mais importante daquele universo de ensino-aprendizagem.

\section{Considerações Finais}

Este artigo discutiu, em que medida, as práticas inerentes ao modelo da Gestão Integrada da Escola (GIDE) implementadas nas escolas estaduais do Rio de Janeiro passaram a fazer parte de suas rotinas, ou seja, em que medida foram institucionalizadas ou não. Recorreu-se à Teoria Institucional porque esta abordagem entende que as mudanças que ocorrem nas organizações são como essenciais à sua existência (DIMAGGIO e POWELL, 2005). Buscou-se analisar o processo de institucionalização das práticas (Administrativas e Pedagógicas) implementadas pela GIDE nas escolas estaduais, na perspectiva dos docentes, à luz das elaborações de Tolbert e Zucker (1999), que destacam três fases que podem caracterizar a 


\section{大 Wsy Eulloahá}

ISSN: 1984-6444 | http://dx.doi.org/10.5902/1984644432139

institucionalização de determinada prática: habitualização, objetificação e sedimentação.

A priori, constatou-se que a implementação da GIDE nas escolas se deu a partir que pressões formais da Secretaria de Educação que, por sua vez, criou mecanismos de controle sistemáticos para verificar se as práticas (Administrativas e Pedagógicas) foram inseridas na rotina escolar. Nestes termos, evidências de habitualização foram verificadas nas práticas mais fáceis de efetuar monitoramento, pois estas foram introduzidas mais rapidamente, uma vez que gestores e professores não poderiam se negar a implementar o que foi solicitado pela Secretaria, sem que fosse registrado. Por exemplo: utilização do sistema Conexão Educação, que modificou a rotina de lançamentos de notas pelos docentes das escolas; utilização do painel de gestão, que possibilitou o acompanhamento dos resultados da escola por toda a comunidade escolar, utilização do Currículo Básico pelos docentes; e participação dos estudantes avaliações externas Saerjinho/bimestral e SAERJ/anual, realizadas pela própria Secretaria de Educação; na utilização do sistema Conexão Educação, que modificou a rotina de lançamentos de notas pelos docentes das escolas; na utilização do painel de gestão, que possibilitou o acompanhamento dos resultados da escola por toda a comunidade escolar e na utilização do Currículo Básico pelos docentes.

Os Agentes de Acompanhamento da Gestão Escolar (AAGEs), também, acompanhavam as escolas, semanalmente, para manter gestores e professores informados das práticas da GIDE; garantir que professores lançassem as notas dos estudantes, no prazo, na plataforma estadual de monitoramento do desempenho dos estudantes; garantir a divulgação dos resultados das avaliações bimestrais e anuais, por meio de gráficos e diagramas, no painel de gestão (mural - criação da GIDE).

Verificou-se, ainda, que as práticas que se sedimentaram se referem, novamente, àquelas que podem ser monitoradas pelos AAGEs, portanto, pela Secretaria de Educação. Mais de $70 \%$ dos docentes informaram que adotaram as novas práticas. No entanto, quanto mais a definição do "que fazer" e o processo de trabalho estavam sob o controle do professor, maior era a dificuldade deste aceitar as novas práticas da Secretaria de Educação e mais difícil para esta última implementar o que pretendia. Em outras palavras, embora os docentes tenham tomado 


\section{THEM Eutioará}

ISSN: 1984-6444 | http://dx.doi.org/10.5902/1984644432139

conhecimento do que deveria ser feito não implicou no fazer. Pelo menos no âmbito da sala de aula, onde são poucas as alternativas de controle e acompanhamento sistemático e diário dos professores.

Note-se que, no que tange às práticas pedagógicas dos docentes, estas, praticamente, não foram alteradas. Este foi um dos principais achados desta pesquisa: no espaço destinado ao exercício da burocracia profissional não ocorreram mudanças significativas. Uma das principais características deste tipo de estrutura é, exatamente, a autonomia individual que permite grande liberdade de controle do próprio trabalho por parte do profissional, como no caso dos docentes em sala de aula (CLABAUGH e ROZYCKI, 1990; BIDWELL, 2001; MINTZBERG, 2003).

Há que se destacar que, provavelmente, a pouca aceitação das práticas da GIDE na rotina do professor em sala de aula, também, se deva à adoção de uma estratégia de caráter mais coercitivo para obter a participação dos docentes, por parte da Secretaria de Educação. Ao mesmo tempo em que este tipo de estratégia gerou adesão às práticas passíveis de monitoramento, provocou resistência quando o professor tinha liberdade de escolha. O que pode ser observado, claramente, quando os docentes, no exercício da sua atividade em sala de aula, onde há maior autonomia, não adotaram as práticas da GIDE. Em outros termos, se verifica um processo de institucionalização das práticas administrativas, mas não das práticas pedagógicas.

Apesar das resistências, ficou evidente que a implementação da GIDE organizou e padronizou práticas administrativas fundamentais ao sistema educacional da rede pública do estado do Rio de Janeiro. Porém, parece não ter avançado nas práticas relativas à sala de aula, ou seja, nas práticas pedagógicas, de acordo com os respondentes. Em outras palavras, os resultados da pesquisa sugerem que as mudanças implementadas e institucionalizadas ocorreram apenas nos processos administrativos, mas não foram extensíveis à sala de aula, de modo a impactar o processo de ensino-aprendizagem.

Provavelmente, a adoção de uma estratégia mais participativa, por parte da Secretaria de Educação, que incluísse os docentes na tomada de decisão do 'que fazer' na sala de aula, poderia ter gerado maior aceitação de inserção de novas práticas organizativas, especialmente, no âmbito da sala de aula. 


\section{Tusm entuará}

ISSN: 1984-6444 | http://dx.doi.org/10.5902/1984644432139

\section{Referências}

ACKOFF, Russell L. Management misinformation systems. Management Science, Pennsylvania, v.14, n.4, dec., 1967. Disponível em http://hkilter.com/courses/609/rlAckoff-Management-Misinformation-Systems.pdf. Acesso em: 10 abr. 2018.

BABBIE, Earl. Métodos de Pesquisa de Survey. Belo Horizonte: Editora UFMG, 2003.

BERGER, Peter; LUCKMANN. Thomas. La construcción social de la realidad. Buenos Aires: Amorrortu, 2001.

BRELÀZ, Gabriela; ALVES, Mário Aquino. O processo de institucionalização da participação na Câmara Municipal de São Paulo: uma análise das audiências públicas do orçamento (1990-2010). Revista de Administração Pública, v. 47, n. 4, p. 803826, 2013.

BIDWELL, Charles. Analyzing schools as organizations: long-term permanence and short-term change. Sociology of Education, v. 74, 100-114, 2001.

BONETTI, Osvaldo Peralta; ODEH, Muna Muhammad; CARNEIRO, Fernando Ferreira. Problematizando a institucionalização da educação popular em saúde no SUS. Interface, v.18, n.2, p. 1413-1426, 2014.

BORGES, Flávio Henrique Moncorvo. A GIDE no contexto de uma escola de Ensino Médio regular noturno no Rio de Janeiro: uma análise das práticas gestoras. Juiz de Fora: Programa de Pós-Graduação em Gestão e Avaliação da Educação Pública (UFJF), 2013.

CLABAUGH, Gary; ROZYCKI, Edward. The school as an organization. In: CLABAUGH, Gary; ROZYCKI, Edward (Eds.). Understanding schools: the foundations of education (Chapter 8). New York, NY: Harper \& Rowe, 1990.

COCHRAN, William G. Sampling Techniques. New York: John Wiley \& Sons, 1977.

DIMAGGIO, Paul Joseph; POWELL, Walter. A gaiola de ferro revisitada: isomorfismo institucional e racionalidade coletiva nos campos organizacionais. Revista de Administração de Empresas, v. 45, n. 2, p. 74-89, 2005.

EISENHARDT, Kathleen. Agency and institutional theory explanations; the case of retail sale compensation. Academy of Management Journal, v. 31, p. 488-511, 1988. 


\section{T- us"

ISSN: 1984-6444 | http://dx.doi.org/10.5902/1984644432139

GODOY, Maria Helena Pádua Coelho; MURICI, Izabela Lanna. Gestão integrada da escola. Curitiba (PR): INDG Tecnologia e Serviços Ltda., 2009.

GOUVEIA, Andréa Barbosa; SOUZA, Ângelo Ricardo. Perspectivas e desafios no debate sobre financiamento e gestão da educação: da Conae a um novo PNE. Educação e Sociedade, Campinas, SP, v. 31, n. 112, p. 789-807, jul./set. 2010.

GUERREIRO, Reinaldo et al. Fatores determinantes do processo de institucionalização de uma mudança na programação orçamentária: uma pesquisa ação em uma organização brasileira. Revista de Contabilidade do Mestrado em Ciências Contábeis da UERJ, v.10, n.1, p.59-76, 2005.

HAIR, Joseph JR. et al. Análise multivariada de dados. Porto Alegre: Bookman, 2009.

Howlett, Michael; Ramesh, M.; Perl, Anthony. Studying public policy: Policy cycles and policy subsystems. Oxford: Oxford University Press, 2003.

IBGE, Instituto Brasileiro de Geografia e Estatística. Cidades. Disponível em: $<$ http://cidades.ibge.gov.br/xtras/perfil.php?lang=\&codmun=330630\&search=||infogr \%E1ficos:-informa\%E7\%F5es-completas>. Acesso em: 20 nov. 2017.

INEP - Instituto Nacional de Estudos e Pesquisas Educacionais Anísio Teixeira. Índice de Desenvolvimento da Educação Básica (IDEB). Brasília: INEP, 2015. Disponível em: <http://portal.inep.gov.br/web/portal-ideb>. Acesso em: 24 nov. 2017.

INEP, Instituto Nacional de Estudos e Pesquisas Educacionais Anísio Teixeira. Estudo exploratório sobre o professor brasileiro com base nos resultados do Censo Escolar da Educação Básica 2007. Brasília: Inep, 63 p, 2009. Disponível em http://portal.mec.gov.br/dmdocuments/estudoprofessor.pdf. Acesso em 02/02/2017.

INEP, Instituto Nacional de Estudos e Pesquisas Educacionais Anísio Teixeira. Índice de Desenvolvimento da Educação Básica (IDEB). Disponível em http://portal.inep.gov.br/web/portal-ideb. Acesso em 02/06/2015.

INEP, Instituto Nacional de Estudos e Pesquisas Educacionais Anísio Teixeira. Estudo exploratório sobre o professor brasileiro com base nos resultados do Censo Escolar da Educação Básica 2007. Brasília: Inep, 63 p, 2009. Disponível em http://portal.mec.gov.br/dmdocuments/estudoprofessor.pdf. Acesso em 02/02/2017. 


\section{educação revista ПTSM

ISSN: 1984-6444 | http://dx.doi.org/10.5902/1984644432139

JOHNSON, Susan Moore; BERG, Jill Harrison; DONALDSON, Morgaen. Who Stays in Teaching and Why: A Review of the Literature on Teacher Retention. The Project on the Next Generation of Teachers. Feb., 2005.

KIRKBESOGLU, Erdem. Strategic reactions of organizations to legal environment: a typology for industries in the process of institutionalization. International Journal of Business, Humanities and Technology, v. 2, n. 3, p. 68-72, 2012.

KOETZ, Carmen Maria; WERLE, Flávia Obino Corrêa. Trajetória do sistema de avaliação do rendimento escolar do Estado do Rio Grande do Sul. Ensaio: Avaliação e Políticas Públicas em Educação, v. 20, n.77, p.677-700, 2012.

MACHADO-DA-SILVA, Clóvis; GONÇALVES, Sandro Aparecido. Nota técnica: a teoria institucional. In: CLEGG, S. R.; HARDY, C.; NORD, W. R. (Orgs.). Handbook de Estudos Organizacionais, v. 1. São Paulo: Atlas, 1999. p. 220-226.

MACHADO-DA-SILVA, Clóvis; FONSECA, Valéria Silva da; CRUBELLATE, João Marcelo. Estrutura, agência e interpretação: elementos para uma abordagem recursiva do processo de institucionalização. Revista de Administração Contemporânea, Curitiba, v. 14, n. spe, p. 77-107, Set., 2010.

MEYER, John W.; ROWAN, Brian. Institutionalized organizations: formal structure as myth and Ceremony. American Journal of Sociology, v. 83, p. 341-63, 1977.

MINTZBERG, Henry. Criando organizações eficazes. São Paulo: Atlas, 2003.

NASCIMENTO, João Paulo Rodrigues; VIEIRA, Maria das Graças. Os desafios da institucionalização do ensino superior na modalidade a distância: a visão dos gestores de uma universidade federal. Ensaio: Avaliação e Políticas Públicas em Educação, v. 24, n.91, p.308-336, 2016.

POWELL, Walter W; DiMAGGIO, Paul. J. The Iron Cage Revisited: Institutional Isomorphism and Collective Rationality in Organizational fields. American Sociological Review, p.147-60, April 1983.

POWELL, Walter W.; DiMAGGIO, Paul. J. The new institutionalism in organizational analysis. Chicago; London: University of Chicago Press, 1990.

PROCHNO, Paulo. Routine assembly: institutionalizing practices in a new setting. In: Anais XXVII ENANPAD, Atibaia, 2003. 


\section{工 WFH edtothâa}

ISSN: 1984-6444 | http://dx.doi.org/10.5902/1984644432139

QUEIROS, Agleildes Arichele Leal; LIMA, Luci Praciano. A institucionalização do trabalho do agente comunitário de saúde. Trabalho, Educação e Saúde, v. 10, n.2, p. 257-281, 2012.

SCHELBAUER, Analete Regina. Da roça para a escola: institucionalização e expansão das escolas primárias rurais no Paraná. História da Educação, v. 18, n.43, 2014.

SCOTT, W. Richard. Institutions and organizations. London: Sage Publications, 2001.

SEEDUC, Secretaria de Estado de Educação. Relatório de Gestão e Políticas Públicas. Rio de Janeiro, $2014 . \quad$ Disponível em: <http://download.rj.gov.br/documentos/10112/2247397/DLFE-72622.

pdf/RGPP2014Parte1.pdf>. Acesso em: 28 jan. 2018.

SEEDUC, Secretaria de Estado de Educação. Relatório de Governança. SEEDUC em números: transparência na educação. Rio de Janeiro, 2013. Disponível em: $<$ http://download.rj.gov.br/documentos/10112/912504/DLFE-

61803.pdf/RELATORIODEGOVERNANCA2013web.pdf>. Acesso em: 28 jan. 2018.

TOLBERT, Pamela; ZUCKER, Lynne. A institucionalização da teoria institucional. Handbook de estudos organizacionais, v. 1, p. 196-219, 1999.

ZUCKER, Lynne. The role of institutionalization in cultural persistence. American Sociological Review, v.41, n.5, p.726-43, 1977.

VALLE, Maria M. de M. O monitoramento do programa de educação do estado do Rio de Janeiro. Juiz de Fora: Faculdade de Educação/CAED. Programa de PósGraduação em Gestão e Avaliação da Educação Pública (UFJF), 2012.

ZUCKER, Lynne. Institutional theories of organization. Annual Review of Sociology, v. 13, p. 443-464. 1987.

\section{Correspondência}

Lucia Helena Esteves Pereira - Mestre em Administração pela Universidade Federal Fluminense

Sandra R. H. Mariano - Professora doutora na Universidade Federal Fluminense Joysi Moraes - Professora doutora na Universidade Federal Fluminense 


\section{Guthoaล̃ó}

ISSN: 1984-6444 | http://dx.doi.org/10.5902/1984644432139

Bruno Francisco Batista Dias - Mestre pelo Programa de Pós-Graduação em Administração da Universidade Federal Fluminense

Universidade Federal Fluminense - Rua Miguel de Frias, 9 Icaraí CEP: 24220-900. Niterói, Rio de Janeiro, Brasil

E-mail: esteves.pereira271@gmail.com - sandramariano@id.uff.br jmoraes@id.uff.br -brunofbd@id.uff.br

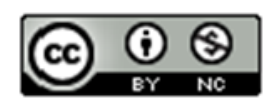

This work is licensed under a Creative Commons Attribution-NonCommercial 4.0 International (CC BY-NC 4.0) 